\title{
SOBRE 0 CONCEITO DE NOEÎN EM PARMÊNIDES
}

\author{
José Lourenço Pereira da Silva \\ Universidade Federal de Santa Maria
}

\begin{abstract}
The verb noeîn and its substantive form nóos belong to the Greek cognitive vocabulary of epic and presocratic literature, meaning an insight of reality or of the truth of an object, that is, a kind of cognition akin to sensory perception in its intuitive and direct features. According to Von Fritz, these concepts underwent an evolution in which Parmenides was a turning-point. In Parmenides, without losing its most important feature as an insight into the nature of things - hence of grasping the being (tò eón) - nóos also works as a logical reasoning. In other words, noeîn-nóos perform a dual function: it is both acquaintance with the ultimate reality and discursive thinking, which argues, infers and deduces. Our main purpose here is to present how Parmenides articulates these two roles of nóos.
\end{abstract}

Keywords: Parmenides, noeîn-nóos, discursive thinking.

Resumo: 0 verbo noeîn e sua substantivação nóos pertencem ao vocabulário cognitivo grego na literatura épica e pré-socrática comunicando a ideia de uma apreensão imediata da realidade ou da verdade de um objeto, isto é, um tipo de cognição análogo à percepção sensível em seu caráter intuitivo e direto. Segundo Von Fritz, esses conceitos passaram por uma evolução na qual Parmênides representa um momento decisivo. Em Parmênides, sem perder o aspecto preponderante de uma intuição da natureza das coisas - portanto de captar o ser (tò eón) - o nóos também opera como raciocínio lógico. Quer dizer, noeîn-nóos exerce uma dupla função: é o contato direto com a realidade última e o pensamento discursivo, que argumenta, infere e deduz. Nosso propósito aqui é mostrar como, em Parmênides, essas funções do nóos se encontram articuladas.

Palavras-chave: Parmenides, noeîn-nóos, pensamento discursivo.

Na História da Filosofia, Parmênides foi o primeiro (ao menos cujos textos foram conservados) a declarar que "o mesmo é pensar e ser" (fr. 3). A breve assertiva comporta problemas desconcertantes, já respondidos de 
variadas maneiras. Os estudiosos não se entendem nem quanto aos significados dos conceitos chaves, ser (eînaı) e pensar (noeîn), nem quanto à exata relação que Parmênides estabelecera entre eles. Qual o sentido do ser? O que significa pensar? E como entender que ambas as coisas, pensar e ser, coincidem? Não trataremos da primeira questão, mas para a leitura que faremos a compreensão do ser como a "verdadeira natureza das coisas", aquilo que em verdade um ente é, é a mais apropriada ${ }^{1}$. Nestas considerações, focalizaremos os conceitos parmenideano de pensar e de pensamento - o inevitável correlato do ser - procurando mostrar, à luz da interpretação de Von Fritz, que as duas acepções básicas em que o verbo noeîn ou suas substantivações nóos e nóéma são tomados conciliam-se para proporcionar o conhecimento mais seguro da verdadeira realidade.

As noções de noeîn ou de nóos ${ }^{2}$ em Parmênides são das mais difíceis de compreender e explicar. De importância capital, os termos noeîn e seus cognatos ocorrem em quase todos os fragmentos da via da Verdade (exceções: fr. 1 e fr. 5) e no fr. 16 da via da Opinião, não recebendo, porém, descrição que mostre claramente seus significados e funções específicas. É quase um consenso entre os exegetas de Parmênides que os termos noeîn e nóos indicam uma operação mental. As opiniões se dividem quanto ao tipo de operação, e, em geral, escolhas são feitas entre, basicamente, estas duas compreensões: o nóos como a capacidade para a apreensão imediata do objeto do conhecimento, assim sobressaindo seu caráter de intuição; ou como realizando o pensamento discursivo e o raciocínio lógico. Os fragmentos parecem apoiar ambas as interpretações.

O verbo noeîn aparece pela primeira vez no poema, sob a forma de infinitivo aoristo, no fr. 2, 2, na declaração feita pela deusa das únicas vias de investigação que há para noēsai. "Pensar" (Penser, Pensare, Denken,

\footnotetext{
1 VERDENIUS (1967), identificando o sujeito do esti no fr. 2, 3 e fr. 8, 2 à alētheia, considera ser o sentido deste conceito "a verdadeira natureza das coisas".

2 A etimologia da palavra nóos é obscura. A hipótese de FRITZ (1974, p. 23) de que derivaria da raiz significando "farejar", "cheirar" não encontra muito respaldo. VIOLA (1987, p. 86-87), seguindo Untersteiner e Kieckers, acredita na origem do substantivo nóos a partir dos verbos néomai - ir, vir - e néō - nadar. A ideia de movimento, destaca Viola, se harmoniza com a ideia de hodós que Parmênides convida a percorrer. A ligação com hodós confirmaria, assim, o sentido primitivo de nóos. Para Viola, em Parmênides, o nóos é o guia seguro que permite percorrer o caminho e que leva aquele que caminha a uma visão (pelo espírito) da coincidência no ser da multiplicidade das coisas sensíveis. A nosso juízo, a etimologia favorecida por Viola põe em relevo 0 caráter intencional do pensamento: o pensamento sempre se volta ao que é.
} 
Thinking) é a tradução usual; em contraste com "conhecer", "entender" propostas por alguns intérpretes e tradutores ${ }^{3}$. A nosso juízo, não há por que se evitar a tradução tradicional desde que se tenha presente que noeîn é mais propriamente compreendido como conhecer ou entender ${ }^{4}$. De fato, é preciso saber que via de investigação é possível seguir, não apenas ter uma noção mais ou menos geral ou vaga. Nesse sentido, mesmo a via do não-ser, impedida porque impensável (anóéton, fr. 8, 17), deve ser conhecida como tal. Tratar-se-ia, neste caso, de um conhecimento de segunda ordem que permite compreender que, rigorosamente, o nóos somente pode dirigir-se para o que é (tò eón), e só a ele ligar-se, operando como uma "apreensão segura" 5 da verdade.

Essa interpretação de noeîn e nóos é defendida por Kurt von Fritz em seu estudo clássico sobre os usos desses termos no pensamento arcaico. Von Fritz sustenta que, "o significado fundamental da palavra noeîn em Homero é 'perceber ou entender uma situação" (to realize or to understand a situation $)^{6}$. Nóos indicaria a faculdade que realiza uma espécie de percepção, um fenômeno cognitivo que toma lugar em contextos tais como da identificação de pessoas (ou deuses) ou objetos que aparecem diferente daquilo que realmente são, ou ainda a apercepção do significado de um evento ou situação antes vista de maneira não acurada. Em suma, o nóos funciona como uma intuição (insight) da natureza real, penetrando mais a fundo e além da aparência externa ${ }^{7}$. É justamente esse sentido que deve assumir o noeîn quando explicitamente associado ao ser (eón, eînat) em passagens cruciais do poema de Parmênides. Cumpre, então, determo-nos em algumas delas.

Mister se faz iniciar pelo disputado fr. 3: "Pois pensar e ser é o mesmo" (tò gàr autò noeîn estín te kaì eînai). O significado dessa linha é

\footnotetext{
${ }^{3}$ KAHN (1969, p. 703); PALMER (2009).

${ }^{4}$ BARNES (1996, p. 158-159; p. 611, n.6) argui para o sentido mais vago de noeîn como simples pensar ou conceber, suposta, em algumas ocorrências, sua falta de compromisso com a verdade e mesmo sua suscetibilidade ao erro. LESHER (1994, p. 27, n. 54) (1999, p. 247, n. 19) endossa a opinião de Barnes. Sobre esse ponto, cf. nossa nota 33 abaixo.

5 MOURELATOS (2008, p. 164).

${ }^{6}$ FRITZ (1974, p. 23). Cf. as qualificações feitas por LESHER (1981).

${ }^{7}$ FRITZ (1974, p. 25) ilustra com os exemplos: a compreensão que tem um indivíduo do perigo iminente com a aproximação de um inimigo como Aquiles; o reconhecimento de Afrodite, na aparência de velha, por Helena, e, em geral, casos em que um indivíduo repentinamente percebe haver más intenções escondidas por trás de atitudes aparentemente amistosas.
} 
nada evidente. Fundamentalmente, os comentadores estão separados em dois grupos: os partidários da leitura idealista e aqueles da leitura realista, com numerosos matizes e motivações cada uma. A distinção básica entre uma posição e outra reside na forma como se considera a relação causal entre pensar e ser, entre o sujeito pensante e o objeto do pensamento: para interpretação idealista, "o pensar mediante seu ato cognitivo constitui aquilo que 'é; para interpretação realista, o que 'é' é a causa do pensar”"

A leitura idealista tem em sua origem Plotino, que cita o verso (fr. 3) de Parmênides como antecedente da por ele propugnada identificação, no plano do inteligível e do conhecimento puramente racional, do pensar com o ser, do pensamento com o objeto do pensamento ${ }^{9}$. No período moderno, Hegel aceita a lição plotiniana de que, para Parmênides, o pensamento produz o $\operatorname{ser}^{10}$; interpretação também adotada por exegetas de inspiração neokantiana que tocaram a doutrina de Parmênides ${ }^{11}$. Entre os scholars contemporâneos, Vlastos, Sedley e Cristal sustentam a identidade do pensar e do ser como implicação inescapável do monismo parmenideano. Para Vlastos, que interpreta a filosofia de Parmênides como uma mistura de misticismo e lógica, o eleata acreditou na identidade de pensador e pensamento; aquele que pensa o Ser é o que ele pensa, e assim participa da divindade e imortalidade do próprio $\mathrm{Ser}^{12}$. Sedley argumenta que "Parmênides não nega que o pensar aconteça, mas uma vez que o ser é tudo que há, ele deve negar que o pensar esteja separado do ser. Assim, devemos considerar ter ele sustentado que o que pensa é, e que o que é pensa." Esta fusão, segundo Sedley, é facilmente compreensível no contexto da primeira filosofia grega, dado o costume dos primeiros pensadores conceberem suas archai como seres viventes ${ }^{13}$. Para Cristal, a identidade do

\footnotetext{
${ }^{8}$ CRISTAL (2002, p. 209).

9 PLOTINO, Enéada V, I, 8: "Le premier qui ait professé cette doctrine [sc. das três hipóstases: o Um, Noûs e a Alma e suas relações] est Parménide, qui identifie l'être [ón] et l'intelligence [noûs] et ne place pas l'être dans les choses sensibles: 'Car, dit il, la pensée est la même chose que l'être'. II ajoute que l'être est immobile, tout en lui accordant la pensée; il refuse à l'être tout mouvement corporel, afin qu'il demeure toujours le même."

10 HEGEL, Vorlesungen über die Geschichte der Philosophie: "Das ist der Hauptgedanke. Das Denken produziert sich, was produziert wird, ist ein Gedanke; Denken ist also mit seinem Sein identisch, denn es ist nichts außer dem Sein, dieser großen Affirmation. Plotin, indem er dies anführt, sagt, „daß Parmenides diese Ansicht ergriff, insofern er das Seiende nicht in den sinnlichen Dingen setzte"."

11 Cf. REALE (1967, p. 221 e segs.).

12 VLASTOS (1946, p. 75).

${ }^{13} \operatorname{SEDLEY}(1999$, p. 120). Os jônicos trataram seus princípios, a matéria do universo, como divino. Melisso, seguidor de Parmênides, concebe seu Um como um ser vivente.
} 
"ato cognitivo com o que ele apreende" é consequência da impossibilidade de diferenciação do Ser demonstrada no fr. 8. Ou seja, o monismo delineado no fr. 8 não admite diferenciação entre pensar e o que é pensado, entre sujeito epistêmico e objeto ${ }^{14}$.

Admitindo que o Ser exista de forma objetiva, isto é, independente da mente e como condição do pensar, a leitura realista evita fazer o Ser parmenideano uma entidade vivente e pensante ${ }^{15}$, assim como confundir o cognoscente com o cognoscível. No quadro de sua interpretação epistemológica de Parmênides, Charles Kahn avança uma explicação dos versos fr. 3, fr. 8, 34 e fr. 6, 1 em que defende certa identidade do noeîn com o eón, mas salvaguarda o realismo. Tomando noeîn no sentido de conhecer ou cognição (knowing, cognition), ele propõe que a identificação entre a cognição e seu objeto, a afirmação verdadeira e o que é afirmado, signifique a realidade (existência) e o ser verdadeiro da cognição e do discurso verdadeiro, como lê o "enigmático" primeiro hemistíquio do verso fr. 6, 1: "Cognição e afirmação devem ser o que é (i. e, devem ser verdadeiras e reais)" 16 . Segundo Kahn, Parmênides julgou existir um isomorfismo entre o conhecimento e a realidade conhecida; e este isomorfismo, o eleata concebeu como identidade. A aproximação é feita com a doutrina aristotélica da identidade do conhecimento em ato com o que é conhecido ${ }^{17}$, ou da faculdade do noûs em ato com as coisas que ela apreende ${ }^{18}$. De acordo com Kahn, a doutrina de Aristóteles não seria uma forma de idealismo, mas algo como um monismo neutro. Não é fácil esclarecer a natureza desta identidade do pensamento com

\footnotetext{
${ }^{14}$ CRISTAL (2002, p. 217 e segs.). Criticando a posição idealista, PALMER (2009, p. 121) mostra como incoerente é a interpretação que colapsa a distinção entre pensar e ser: "Se o Ser parmenideano fosse ao mesmo tempo pensar e objeto de seu próprio pensamento, então ele já violaria o princípio da identidade de pensar e ser. Na medida em que é pensamento, não é pensar, de modo que seu ser não pode ser idêntico com sua atividade de pensar, mas tem também que consistir pelo menos em parte em seu ser tal como ser pensamento."

${ }^{15}$ De fato, movimento e vida ou alguma atividade cognitiva não foram elencados nos atributos (semata) do Ser.

${ }^{16} \mathrm{KAHN}$ (1969, p. 722): Either knowledge and true speech are Being or they are nothing at all. (...) The fact that eón in Greek means "truth" as well as "Being" makes it all the more natural for him to insist that true statement and cognition cannot be nothing. It is falsehood and error which belong with tò me ón, "what is not (so)". Na análise sintática que faz da frase fr.6, 1, Kahn considera tò legeîn e noeîn como os sujeitos de uma frase no infinitivo - cujo verbo seria émmenai - e toma eón como predicado. Cf. (1969, 722, n. 6).

${ }^{17}$ ARISTÓTELES, De Anima, 431a1: tò d' auto estin hē kat' enérgeian epistēmē tōi prágmati.

${ }_{18}$ ARISTÓTELES, De Anima, 431b17: holōs dé ho noûs estin ho kat' enérgeian ta prágmata [noōn]. Et passim.
} 
seu objeto. Mas uma característica suficientemente evidente, tanto em Parmênides quanto em Aristóteles, é o fato de nela haver uma "curiosa assimetria”, pois, escreve Kahn:

é sempre o noûs ou noeîn que é identificado com - ou reduzido a - seu objeto, nunca conversamente. Parmênides nunca disse que Ser é pensar (ou ser-pensante). Aristóteles não diz que os objetos inteligíveis são eles mesmos inteligências [exceção feita ao primeiro motor]. Esta assimetria geral reflete o quanto tal monismo permanece 'realista': conhecer é fundado no Ser, ciência e lógica repousam na ontologia; a mente não impõe suas formas mas recebe-as do objeto que ela conhece $^{19}$.

Nosso autor ressalta com toda propriedade o realismo parmenideano. Todavia, na explicação das linhas em consideração insistir que, para Parmênides, o conhecimento e o discurso verdadeiro existem e são verdadeiros é afirmar uma platitude contra a qual parece não caber argumento. Necessário se faz tentar compreender por que há a relação entre pensar e ser, ou seja, a razão de existir o conhecimento verdadeiro, questão que a interpretação de Kahn parece não considerar. Outra leitura do fr. 6, 1-2 e, especialmente, uma análise da dificílima passagem fr. 8, 34-36 permitem, supomos nós, entender o vínculo necessário entre o pensamento e o ser. Das diversas traduções apresentadas ${ }^{20}$ para os versos fr. 6, 1-2, a nosso ver, Cordero (seguindo Tarán) oferece a mais simples e fiel. Na tradução de Cordero, o fr. 6, 1a afirma: "É necessário dizer e pensar o que é" ("Il est

\footnotetext{
${ }^{19}$ KAHN (1969, p. 724); cf. também (2007, p. 5-7).

20 Algumas: SANTOS (2002): É necessário que o ser, o dizer e o pensar sejam; pois podem ser, enquanto o nada não é: nisto te indico que reflitas. SOUZA (1978): Necessário é o dizer e pensar que (o) ente é; pois é ser, e nada não é; isto eu te mando considerar. BORNHEIM (1998): Necessário é dizer e pensar que só o ser é; pois o ser é, e o nada, ao contrário, nada é; afirmação que bem deves considerar. PALMER (2009): It is necessary to say and to think that What Is is; for it is to be, but nothing it is not. These things I bid you ponder. REALE (1991): È necessario il dire e il pensare che l'essere sia: infatti l'essere è, il nulla non è: queste cose ti esorto a considerare. DIELS (1897): Das Sagen und Denken muss ein Seindes sein. Denn das Sein existirt, das Nichts existirt nicht; das heiss ich Dich wohl zu beherzigen.
} 
nécessaire de dire et de penser ce qui est") ${ }^{21}$. Essa asserção, Cordero comenta, aparece como consequência da afirmação da via da Verdade no fr. 2; como seu "lado gnosiológico". A importância do discurso e do pensamento em Parmênides é determinada pelo conteúdo da via da Verdade: "só a verdade"... "pode ser pensada e mencionada" 22 . Essa verdade, na opinião de Cordero, é o fato que o ser existe, ou que não ser não é possível, fato que se apresenta com absoluta necessidade tornando também necessários o pensamento e o enunciado que o declara. Cumpre observar, porém, que, a rigor, Parmênides não diz qual o conteúdo da Verdade que o noeîn e o legeîn têm que deter. A tese de fr. 6, 1-2 é a pura e simples afirmação da conexão necessária entre o pensamento, o discurso e o ser, justificada pela impossibilidade do não-ser.

No fr. 8, 34-36 Parmênides formula mais completamente o princípio da relação entre pensar e ser. tautòn d'estì noeîn te kai hoúneken ésti nóēma. ou gàr áneu toû eóntos, en hōi pephatisménon estín, heurēseis tò noeîn ${ }^{23}$. Um dos pomos da discórdia na interpretação dessas linhas consiste no valor a atribuir a hoúneken no fr. 8, 34. Mais adequado, nos parece, é tomá-lo no duplo sentido final e causal (tò hoû héneka; hoû hoúneka) ${ }^{24}$ e adotar a seguinte tradução: "o mesmo é para pensar e aquilo por que é pensamento" 25 . Trata-se, pois, da asserção de que o Ser, sem o qual não há

${ }^{21}$ CORDERO (1984, p. 112). Todo o verso: khrē tò légein tò noeîn t'eòn émmenai, ésti gar eînai mēdèn d'ouk éstin. Cordero acredita que "eón é o objeto de tò legeîn e de tò noeîn, e que os dois infinitivos, no acusativo, se relacionam com a expressão khrē émmenai".

22 CORDERO (1984, p. 113).

${ }^{23}$ Algumas traduções: SOUZA (1978): $O$ mesmo é pensar e em vista de que é pensamento. Pois não sem o que é, no qual é revelado em palavra, acharás o pensar. SANTOS (2002): 0 mesmo é o que há para pensar e aquilo por causa de que há pensamento. Pois, sem o ser - ao qual está prometido - não acharás o pensar. BORNHEIM (1998): o mesmo é pensar e o pensamento de que o ser é, pois jamais encontrarás o pensamento sem o ser, no qual é expressado. CORDERO (1984): Penser et ce pourquoi la pensée est, sont la même chose; car sans ce qui est, grâce auquel il est énoncé, tu ne trouveras pas le penser. REALE (1991): Lo stesso è il pensare e ciò a causa del quale è il pensiero, perché senza l'essere nel quale è espresso, non troverai il pensare. PALMER (2009): The same thing is both for understanding and that because of which there is understanding. For not without What Is, depending on which it has been expressed, will you find understanding (...). MOURELATOS (2008): And the same is to think of and wherefore is the thinking. For not without what-is, en hōi pephatisménon estín [to which it stands committed, cf. p. 172], will you find thinking (...). DIELS (1897): Denken und des Gedankens Ziel is eins; den nicht ohne des Seindes, in dem sich jenes ausgeprochen findet, kannst Du das Denken antreffen.

24 Uma alternativa é considerar hoúneken = hóti, que; então o verso diria a mesma coisa é o pensar e 0 pensar que é, ou ainda: a mesma coisa é o pensar e o pensamento que afirma 'é'. Cf. REALE (1991, p. 105, n. 34). CORDERO (1984, p. 114) dá o motivo da impropriedade de hóti nesta ocorrência.

${ }^{25}$ Quase a mesma tradução de SANTOS (2002). 
pensamento, a um só tempo é o destino (télos) e a condição do pensar. Como explica Mourelatos (na mais persuasiva interpretação do compromisso da mente com a realidade em Parmênides), estì noeîn, "há para pensar, para conhecer" (is there to think, to know), indica a permissão, enquanto hoúneken ésti nóēma, "por que é pensamento" (wherefore is the thinking) indica a obrigação ${ }^{26}$. O ser é o que está aí para ser pensado e o objetivo ou meta inexorável do pensar ${ }^{27}$, ou do pensamento genuíno. Essa última ideia é confirmada pela também controvertida expressão en hōi pephatisménon estín, comumente traduzida "no qual é enunciado (expressado, revelado)", mas que Mourelatos, novamente, dá o melhor sentido lendo "a que está prometido" (to which it stands committed) ${ }^{28}$. Podemos assim traduzir fr. 8, 35-36: "Pois sem o ser, a que ele está prometido, não encontrarás o pensar"29, e assumir o resultado de Mourelatos: o eón não é apenas o possível mas o objeto necessário da mente ${ }^{30}$. A identidade pensar e ser pode, então, ser entendida como inseparabilidade e conformidade do pensar ao ser.

Essa inseparabilidade é também declarada no fr. 4: “(...) as coisas que estão ausentes (apeónta), para o pensamento (noōi) estão firmemente presentes (pareónta), pois não separarás o ser da sua continuidade com o ser" $(\ldots)^{31}$. Como entendemos, a ideia parece ser que o nóos intui e reconstitui para si o eón ${ }^{32}$, o qual se apresenta ao pensamento como sua única condição

${ }^{26}$ MOURELATOS (2008, p. 168): The first guarantees the presence or the availability of a certain object. But it posits no obligation for mind to seek it. The second posits the obligation, but gives no guarantee of the object's availability. The first clause says "you may"; the second clause says "you must".

${ }^{27}$ MOURELATOS (2008, p. 169): From the viewpoint of mind, B8, 34 contains the striking doctrine that noēma is about, our for the sake of, or is compelled by eón.

28 Interpretando Mourelatos en hōi ... estín no sentido de "to depend on, to rely upon, to be under authority of"; e aproximando o sentido do particípio pephatismenon ao sentido do mesmo verbo phatízō em 8, 60: "dar", prometer, conferir, confiar. "Correspondingly, a pephatisménon nóēma would be a thought not only "spoken" or "declared", but also "bestowed" or committed" (2008, p. 172).

${ }^{29}$ Essa tradução é muito próxima à de SANTOS (2002).

30 MOURELATOS (2008, p. 175). Contra a tradução de nóos por mente, intelecto, inteligência, veja-se FRONTEROTTA (2007, p. 13, n. 22).

31 Última cláusula da tradução de SANTOS (2002).

32 Em uma leitura que chama heterodoxa, MARQUES (2007, p. 98 e segs.) propõe que a "inteligência" ou "percepção inteligente" - sua tradução de nóos - é o que permite tomar consciência da unidade do universo, reunindo a multiplicidade das aparências, os entes no plano da experiência, prima facie separados, na unidade do ser. Como instrumento do olhar que aproxima seres ausentes e ser, tornando aqueles seres presentes, a inteligência pode restituir todo o universo, "que deve ser visto sob a perspectiva do que é"; a inteligência "institui a lei do mesmo, da estabilidade e da unidade." Algo em certo sentido semelhante é mantido por FRONTEROTTA (2007, p. 17) quando defende que noeîn e nóos se referem a uma forma de percepção imediata que, sem desligar-se da atividade sensível, vai 
de possibilidade; de modo que é necessário que o nóos tenha sempre presente o que é. Muito lúcidas a esse respeito afiguram-se nos, então, as palavras de Spinelli: "Posta fora de nós, antes de tudo a realidade é reconstituída racionalmente dentro de nós" 33 .

Com efeito, é equívoco crer que o nóos se dirige ao ser para manter-se numa estática e silenciosa contemplação de seu objeto. $O$ pensamento não somente "Vê", mas também argumenta. De fato, Parmênides é o primeiro filósofo, como bem destaca Cornford, "a oferecer uma prova lógica rígida, em vez de fazer declarações dogmáticas" 34 . Esse caráter da atividade filosófica de Parmênides induziu Cornford a afirmar que, para o eleata: "A inteligência (nóos), na qual punha toda a sua confiança, era a faculdade de raciocinar, argumentar ponto a ponto e deduzir conclusões seguras de axiomas incontestáveis" ${ }^{35}$. Em nossa concepção, o nóos parmenideano não se confunde com a capacidade do raciocínio lógico simpliciter, como pretendido por Cornford, mas tem o poder de exercê-lo como uma de suas funções precípuas.

Efetivamente, ao jovem, já removido do caminho dos mortais, no fr. 7 a deusa exorta a não deixar seu pensamento (nóēma) seguir a via dos que pretendem que sejam as coisas que não são $(m \bar{e} \text { eónta })^{36}$, iludindo-se pelo

além. Seria um tipo de visão sinóptica capaz de perceber a existência e presença de todas as coisas, inclusive as ausentes. Noeîn seria, na interpretação de Fronterotta, a faculdade que generaliza a partir dos dados da experiência e que fornece uma representação geral. O nóos apreende o eînai do que the é imediatamente dado. Não se deve, porém, compreender este ser como ser da cópula, nem como ser metafísico ou objeto inteligível, posto tratar-se da existência dos objetos da experiência cotidiana. $\mathrm{O}$ que parece estar em questão é a exigência mínima de uma epistemologia realista, ou seja, haver alguma coisa dada para ser pensada e concebida. O passo não é avançado, segundo Fronterotta, para distinguir o pensar da percepção sensível, tampouco separar objetos dos sentidos e objetos do pensamento. Se atrativa em aspectos importantes, a leitura de Fronterotta nos parece, todavia, incompleta, sobretudo por não reconhecer a função de pensamento discursivo que o nóos também exerce no Poema.

${ }^{3}$ SPINELLI (1999, p. 28). Prossegue Spinelli: "dado que não há como separar o ente de si mesmo (...) e que não conseguimos saber do que "é" o que "não é", segue-se que, do que "é", do que existe assim de um determinado modo (nos termos da determinação natural), não há como conhecê-lo "sendo" diferentemente. Limitado pelas possibilidades de discurso ou enunciados, o nosso pensamento está submisso não só a determinados limites naturais de seu modo de ser em particular, mas também do existir em geral.

${ }^{34}$ CORNFORD (1952, p. 117).

${ }^{35}$ CORNFORD (1952, p. 117).

${ }^{36}$ A resposta mais plausível para a questão da suscetibilidade do nóos ao erro ou de perseguir o não-ser (cf. fr.6,5; fr. 8, 17; fr. 16) é aquela aduzida por MOURELATOS (2008). O vínculo do pensar com o ser é uma "necessidade normativa". "The relation belongs not to the realm of fact or to psychology, but to an ideal, or normative realm - at the level of one's logical subconscious" (p. 176). "The concept of noein- 
hábito originado das repetidas experiências, e sim julgar ou discernir com a razão ou através do discurso (krînai dè lógōi $)^{37}$ o teste (élenkhos) de realidade por ela fixado. A esse conselho, segue-se a demonstração, por meio de uma lógica férrea, dos sinais do eón: que é ingênito (agenēton), indestrutível (anōlethón), homogêneo (hoúlon mounogenés), inabalável-imóvel (atremès, akínēton), perfeito (telestón), um (hén) e contínuo (synekhés) (fr. 8, 3-6; 26).

A título de ilustração, vejamos a visitada prova do caráter ingênito do ser.

Não foi nem será, pois é agora um todo homogêneo, uno, contínuo. Com efeito, que origem lhe investigarias? Como e onde se acrescentaria? Nem do não-ser te deixarei falar, nem pensar: pois não é dizível, nem pensável, visto que não é. $\mathrm{E}$ que necessidade o impeliria a nascer, depois ou antes, começando do nada? E, assim, é necessário que seja de todo, ou não. Nem a força da confiança consentirá que do não-ser nasça algo ao pé do ser. Por isso nem nascer, nem perecer, permite a Justiça, afrouxando as cadeias, mas sustém-nas: esta é a decisão acerca disso - é ou não é -; decidido está então, como necessidade, deixar uma das vias como impensável e inexprimível (pois não é via verdadeira), enquanto a outra é e é autêntica. (fr. 8, 5-18. Tradução de SANTOS).

$\mathrm{O}$ argumento pode ser assim reconstituído. Se o Ser fosse gerado, teria de ser gerado do Ser ou do Não-ser. Ora, se fosse gerado do Ser, o Ser precederia a sua própria geração, mas isso é o mesmo que dizer não haver geração. Do não-ser tampouco poderia se gerar o Ser, porque seria supor que o Ser tivesse sido um não-ser, uma flagrante contradição, impossível, pois, de manter-se. Portanto, não há geração para o Ser (nem perecimento pela mesma lógica). Trata-se aqui do procedimento, tipicamente eleático, da demonstração

nóos appears at three levels here: At the deepest level we come to see in a clear and rigorous sense that noein is of, about, because of, or for the sake of, what-is (as the latter is understood after B8). At the surface level, this "ontological commitment" is felt as a preference for expressions couched in positive terms. But between these two levels a certain gap develops - the gap between intention and performance. The fault is not on the side of what-is, for it has pistis. It is we mortals who somehow violate our implicit pledge (cf. pephatismenon) to the real" (p. 177).

${ }^{37}$ SNELL (1953, p. 149): "a divindade, longe de silenciar o pensamento dos homens, na realidade ajudao a expressar-se no discurso". 
indireta ou da redução ao absurdo (reductio ad absurdum). Para provar a falsidade da premissa sob consideração, Parmênides estabelece uma dicotomia, e sobre esta dicotomia ele constrói um dilema: se $h$, então ou $p$ ou não- $p$; mas $p$ é impossível, assim como não- $p$; portanto $h$ deve ser falso ${ }^{38}$. O método não visa, provavelmente, a descoberta de verdades novas, mas revestir de certeza o conhecimento já possuído.

Assim, para confirmar-se na verdade, na apreensão do eón, o nóos desempenha também a função do lógos, do pensamento discursivo. Nesse sentido, a interpretação de Kurt von Fritz afigura-se nos conclusiva:

É ainda a função primária do noos estar em contato direto com a realidade última. Ele alcança esta realidade última não somente no fim e como resultado do processo lógico, mas de certa maneira está em contato com ela desde o começo, uma vez que, como Parmênides vezes reiteradas aponta, não há noos sem o eon, no qual ele se desdobra. Na medida em que o difícil pensamento de Parmênides pode ser explicado, o processo lógico parece ter meramente a função de clarificar e confirmar o que, de certa maneira, tem estado no noos desde o início e de limpá-lo de todos os elementos estranhos. ${ }^{39}$

38 SCOLNICOV (2003, p. 5). Estamos de pleno acordo com a representação de Parmênides que oferece Scolnicov: "Parmenides may be said to be the first Cartesian philosopher. He is the first to tackle the problem of method and to make truth dependent on it. He does so explicitly: witness his insistence on hodos, the 'way', and on the path that 'leads to truth'. And he is Cartesian also in the method he favors: an absolutely certain, undeniable, primordial intuition is attained, and consequences are deduced from it. That fundamental rational intuition takes absolute priority over common perception, and truth is to be reconstructed from it according to strict rules of procedure. Even if Parmenides' method is not Descartes's in its details, still, like Descartes, the Eleatic philosopher reaches his conclusions starting from a premise considered as self-evident and as taking precedence over any other proposition one could entertain. The certainty of the conclusions is guaranteed by the certainty of this primary intuition (and also, of course, by the soundness of the procedure; but, as we shall see presently, the content of that intuition is intimately bound up with the method itself). No conclusion can be more certain than the premises from which it derives, and nothing is independently certain except the basic premise" (2003, p. 4). Para uma visão diferente, em que a experiência e a percepção sensível assumem maior importância na estruturação do conhecimento parmenideano, veja-se SPINELLI (1999) e CASERTANO (2007). Em geral, é conforme o reconhecimento do valor e relevância epistêmica da física exposta na via da Opinião, e de sua articulação com as afirmações sobre o Ser na via da Verdade, que se confere mais ou menos importância à empiria e à sensação em Parmênides.

${ }^{39}$ FRITZ (1974, p. 52): "It is still the primary function of the noos to be in direct touch with ultimate reality. It reaches this ultimate reality not only at the end and as a result of the logical process, but in a way is in touch with it from the very beginning, since, as Parmenides again and again points out, there is no noos 
Podemos concluir ressaltando que, em Parmênides, noeîn-nóos sinonimiza com conhecer. É o poder ou faculdade de compreender a verdadeira natureza das coisas e de demonstrá-la. Assim, o caráter intuitivo e o aspecto argumentativo não conflitam entre si; ao contrário, se imbricam para tornar firme e evidente - necessária nos termos de Parmênides - a compreensão do objeto intencionado. Parece não ser outra a ideia fundamental de saber (epistēmē) que os filósofos compartilharão e tentarão explicar a possibilidade, a natureza e a origem.

without the eon, in which it unfolds itself. In so far as Parmenides' difficult thought can be explained, the logical process seems to have merely the function of clarifying and confirming what, in a way, has been in the noos from the very beginning and of cleansing it of all foreign elements." 


\section{Referências}

ARISTOTLE. De Anima. Translation, introduction and notes by R. D. Hicks, Cambridge: Cambridge University Press, 1907.

BARNES, J. The Presocratic Philosophers. London, New York: Routledge, 1996. Reprinted.

BORNHEIM, G. (org.). Os filósofos pré-socráticos. 14º ed., São Paulo: Cultrix, 1998. BOUILLET, M.-N. Les Ennéades de Plotin. Tomo III. Tradução, notas e comentários. Paris: Hachette, 1861.

CASERTANO, G. "Verdade e erro no Poema de Parmênides". Anais de Filosofia Clássica, vol. 1, n. 2, 2007, p. 1-16.

CORDERO, N.-L. Les Deux Chemins de Parménide. Paris, Bruxelles: Vrin, Ousia, 1984.

CORNFORD, F. M. Principium Sapientiae - The origins of Greek philosophical thought. Cambridge: Cambridge University Press, 1952. Tradução portuguesa: Principium Sapientiae - As origens do pensamento filosófico grego. $3^{\circ}$ ed., Trad. M. M. Rocheta dos Santos, Lisboa: Gulbenkian, s/d.

CRYSTAL, I. "The scope of thought in Parmenides". Classical Quarterly, vol. 52, n. 1, 2002, p. 207-219.

DIELS, H. Parmenides Lehrgedicht. Berlin: Georg Reimer, 1897.

FRITZ, K. von. "Nous, Noein, and their derivatives in Pre-Socratic Philosophy (Excluding Anaxagoras)". In: MOURELATOS, Alexander P. D. (ed.). The PreSocratics. A Collection of Critical Essays. New York: 1974, p. 23-85. Originalmente: Classical Philology,40, 1945, p. 223-242; 41, 1946, p. 12-34.

FRONTEROTTA, F. "Some remarks on noein in Parmenides". In: STERN-GILLET, S. and CORRIGAN, K. (eds.). Reading Ancient Texts. Volume I: Presocratics and Plato. Essays in Honour of Denis O'Brien. Leiden, Boston: Brill, 2007, p. 3-20.

GUTHRIE, W. K. C. A History of Greek Philosophy, vol. II, Cambridge: Cambridge University Press, 1990. Reprinted.

HEGEL, G. W. F. Vorlesungen über die Geschichte der Philosophie. Band I. Leipzig: Reclam, 1971. Texto a partir da edição da Hegel's Werke. Herausgegeben von D. Karl Ludwig Michelet. Berlin, 1833.

KAHN, C. "The Thesis of Parmenides". Review of Metaphysics, vol. 22, n. 4, 1969, p. 700-724.

"Algumas questões controversas na interpretação de Parmênides". Anais de Filosofia Clássica, vol. 1, n. 2, 2007, p. 33-45. 
LESHER, J. "Perceiving and Knowing in the Iliad and Odyssey". Phronesis, vol. 26, n. 1, 1981, p. 2-24.

. 'Parmenides' Critique of Thinking: the poludēris elenchos of Fragment 7”. Oxford Studies in Ancient Philosophy, vol. 2, 1984, p. 1-30.

. "The Emergence of philosophical interest in cognition". Oxford Studies in Ancient Philosophy, vol. 12, 1994, p. 1-34.

. "Early interest in knowledge". In: LONG, A. A. (ed.). Early Greek Philosophy. Cambridge: Cambridge University Press, 1999, p. 225-249.

MARQUES, M. P. “O Frag. 4 de Parmênides”. Anais de Filosofia Clássica, vol. 1, n. 2, 2007, p. 91-105.

MOURELATOS, A. P. D. The Route of Parmenides - revised and expanded edition. Las Vegas, Zurich, Athens: Parmenides Publishing, 2008.

PALMER, J. Parmenides and Presocratic Philosophy. Oxford: Oxford University Press, 2009.

REALE, G. (org.). E. Zeller - R. Mondolfo. La Filosofia dei Greci nel suo sviluppo storico. Parte I: I Presocratici. Volume II: Eleati. Firenze: La Nuova Italia, 1967.

REAle, G. e RUGGIU, L. Parmenide. Poema Sulla Natura. Traduzione e note di Giovanni Reale; Saggio introduttivo e Commentario di Luigi Ruggiu. Milão: Rusconi, 1991.

SANTOS, J. T. Parmênides. Da Natureza. Tradução, notas e comentários. São Paulo: Loyola, 2002.

- "Presença da Identidade Eleática na Filosofia Grega Clássica.” Journal of Ancient Philosophy, vol. III, n. 2, 2009, p. 1-41. Disponível em http://www.filosofiaantiga.com/documents/Trindadeeleatismo.pdf. Acesso em 02 de agosto de 2010.

SCOLNICOV, S. Plato's Parmenides - Translated with Introduction and Commentary. Berkeley, Los Angeles, London: University of California Press, 2003.

SEDLEY, D. "Parmenides and Melissus". In: LONG, A. A. (ed.). Early Greek Philosophy. Cambridge: Cambridge University Press, 1999, p. 113-133.

SNELL, B. The Discovery of Mind - The Greek origins of European Thought. Trad. T. G. Resenmeyer. Oxford: Blackwell, 1953. Tradução portuguesa: A descoberta do espírito. Trad. Artur Morão. Lisboa: Edições 70, s/d.

SOUZA, J. C. de. "Parmênides de Eléia. Fragmentos". In: __-_-_ (org.). Os PréSocráticos. Fragmentos, Doxografia e Comentários. São Paulo: Abril Cultural, 1978, p. $141-145$.

SPINELLI, M. "Dois temas em Parmênides: Conhecimento, Verdade e Opinião/Ser, Dizer e Pensar”. O que nos faz pensar, n. 13, 1999, p. 5-31. 
VERDENIUS, W. J. “Parmenides B 2, 3”. Mnemosyne, vol. 15, n. 3, 1962, p. 237. VIOLA, C. "Aux origines de la gnoséologie: réflexions sur le sens Du Fr. IV du Poéme de Parménide.” In: AUBENQUE, P. (org.). Études sur Parménide, II, Paris: Vrin, 1987, p. 69-101.

VLASTOS, G. "Parmenides' Theory of Knowledge". Transactions and Proceedings of the American Philological Association, vol. 77, 1946, p. 66-77.

Email: jlourenco30@yahoo.com.br

Recebido em: Novembro/2010 Aprovado em: Dezembro/2010 